\title{
Social Influences on the Arginine Vasotocin System Are Independent of Gonads in a Sex-Changing Fish
}

\author{
Katharine Semsar and John Godwin \\ Department of Zoology and W. M. Keck Center for Behavioral Biology, North Carolina State University, Raleigh, North Carolina 27695-7617
}

\begin{abstract}
Many neuropeptide systems subserving sex-typical behavior are dependent on sex steroids for both their organization early in life and activation during maturity. The arginine vasopressin/vasotocin (AVP/AVT) system is strongly androgen dependent in many species and critically mediates responses to sociosexual stimuli. The bluehead wrasse is a teleost fish that exhibits a female-to-male sex change in response to social cues, and neither the development nor the maintenance of male-typical behavior depends on the presence of gonads. To examine social and gonadal inputs on the AVP/AVT system in the preoptic area (POA) of the hypothalamus, we conducted three field experiments. In the first experiment, we found that AVT mRNA abundance is higher in sex-changing females that attain social dominance and display dominant male behavior than in subordinate females, regardless of whether the dominant females were intact or ovariectomized. However, AVT-immunoreactive (IR) soma size in the gigantocellular POA (gPOA), but not in the magnocellular or parvocellular POA, increased only when females were displaying both dominant male behavior and had developed testes. In the second experiment, castration of dominant terminal-phase males had no effect on AVT mRNA abundance or any behavior we measured but did increase gPOA AVT-IR soma size compared with sham-operated controls. In the third experiment, 11-ketotestosterone implants in socially subordinate, ovariectomized females had no effect on either AVT mRNA abundance or AVT-IR soma size compared with controls. These results demonstrate that the AVT neural phenotype in the bluehead wrasse can be strongly influenced by social status, and that these social influences can be manifested independent of gonads.
\end{abstract}

Key words: arginine vasotocin; neuropeptide; androgens; gonadal steroids; social behavior; reproductive behavior; 11-ketotestosterone; preoptic area; field study

\section{Introduction}

Gonadal sex steroids typically play key roles in the organization of sex-typical behavior in many vertebrates. Steroids can influence behavior by directing neural growth, connectivity, and neurohormone systems in the brain that are important in sex-typical behavior (Arnold and Breedlove, 1985; Sachs and Meisel, 1994; De Vries and Simerly, 2002). An important influence on maletypical behavior is the interaction between androgens and the arginine vasopressin/vasotocin (AVP/AVT) system, a key neuropeptide mediator of social behavior. During both development and adulthood in numerous species, castration and androgen inhibitors decrease forebrain AVP/AVT immunoreactivity and mRNA levels, AVP/AVT receptor expression, and behaviors mediated by these peptides, whereas androgen replacement reverses these effects (for review, see Goodson and Bass, 2001; De Vries and Simerly, 2002).

However, the organization of sex-typical behavior in species with environmental sex determination may be mediated by factors other than gonadal steroids. For example, temperature di-

Received Nov. 18, 2002; revised Feb. 27, 2003; accepted March 10, 2003.

This research was supported by National Institutes of Health Grant MH-58271 (J.G.), a W. M. Keck Behavioral Biology Predoctoral Fellowship, National Research Service Award MH-12603, and National Science Foundation Doctoral Dissertation Improvement Grant 0206677 (K.S.). This is a publication of the W. M. KeckCenter for Behaviora Biology at North Carolina State University. We thank Robert Warner, Stephanie Neal, Michelle Graham, Frederique Kandel, Heidi Perreault, Shaara Ainsley, Nathan Bachelor, and Andrew Branson for help with this project and two anonymous reviewers for their comments on a previous version of this manuscript.

Correspondence should be addressed to John Godwin, North Carolina State University, 115 Clark Laboratories, Zoology Department, Raleigh, NC 27695-7617. E-mail: John_Godwin@ncsu.edu.

Copyright $\odot 2003$ Society for Neuroscience $\quad$ 0270-6474/03/234386-08\$15.00/0 rectly affects both brain morphology and function in the leopard gecko, Eublepharis macularius, a species with temperaturemediated sex determination (Crews et al., 1996). In the bluehead wrasse (Thalassoma bifasciatum), a sex-changing teleost fish, the dominant male sexual phenotype develops when large females become socially dominant (Warner, 1988; Warner and Swearer, 1991). Importantly, behavioral sex change can be very rapid, and ovariectomy does not prevent the development of male behavior in socially dominant females (Godwin et al., 1996). Therefore, the bluehead wrasse is a useful model for studying the effects of social environment on the function of neural systems subserving sextypical social behavior.

Bluehead wrasse populations include females and initialphase (IP) and terminal-phase (TP) males. Territorial TP males actively defend spawning sites where they court and spawn with females (Warner, 1988). Removing TP males from small reefs induces behavioral and morphological sex change in the largest females (Warner and Swearer, 1991; Godwin et al., 1996). Several days after testes begin developing, 11-ketotestosterone (11KT) levels increase (our unpublished data). Analogous to dihydrotestosterone in tetrapods, $11 \mathrm{KT}$ mediates male secondary sexual character development in fish (for review, see Borg, 1994; Grober and Bass, 2002). However, unlike gonadal change, the onset of male-typical behavior in females can occur within minutes to hours (Warner and Swearer, 1991) and is correlated with increases in hypothalamic AVT mRNA within 2-3 d [the earliest time point sampled by Godwin et al. (2000)]. Furthermore, AVT is necessary for the display of male behavior during early sex change (our unpublished data) and is both necessary for and can 
induce the display of territorial behavior in intact TP males (Semsar et al., 2001).

Because the acquisition of dominant male behavior in bluehead wrasses does not depend on testes but does depend on AVT, we tested the interactions of social status, gonadectomy, and androgen replacement on the AVT phenotype of free-living bluehead wrasses. Specifically, we hypothesized that: (1) AVT phenotype would differ in sex-changing females attaining social dominance compared with subordinate females, regardless of gonadal status, (2) AVT phenotype and territorial behavior in TP males would be unaffected by castration, and (3) AVT phenotype in socially subordinate, ovariectomized females would be unaffected by $11 \mathrm{KT}$ administration.

\section{Materials and Methods}

Study sites. The field portions of the experiments examining the effects of ovariectomy and social status on the development of the AVT phenotype during sex change were conducted from May through July of 2000 and 2001 on small patch reefs with one to four spawning sites in Teague Bay, St. Croix, and the U.S. Virgin Islands (reefs 4, 9a, 9b, 10, 12, 14, 16b, 18, and 21) [for description of reefs, see Gladfelter and Gladfelter (1987)]. Experiments examining the role of castration on the maintenance of the AVT phenotype during TP male dominance were conducted from May through August 2000 and 2001 on large patch reefs with five to nine spawning sites in Teague Bay (reefs 6, 11, 13, and 22). The experiment examining the role of $11 \mathrm{KT}$ on the development of the AVT phenotype under social inhibition was conducted in April and May of 2002 on coral patch reefs in the lagoon of Glover's Reef Atoll, Belize [for description of reefs, see Stoddart (1962)].

Field experiment 1: social and gonadal influences during sex change. This experiment was designed to test the interactions of social and gonadal influences on the AVT system in sex-changing fish using experimental groups that provide clear behavioral contrasts [previously characterized by Godwin et al. (1996)]. In 2000, we captured all IP individuals (both females and males) that were $>45 \mathrm{~mm}$ standard length (SL) from small patch reefs and permanently relocated IP males to different reefs. We either ovariectomized or sham-operated the largest five to eight females (range, 50.1-74.9 mm SL; mean, $61.6 \mathrm{~mm}$ ) as described by Godwin et al. (1996), balancing treatment across body size. We tagged the experimental females for individual identification using beaded floy tags (Warner and Schultz, 1992; Semsar et al., 2001) and returned them to their home reefs on the day of capture after surgeries. After allowing $2 \mathrm{~d}$ of recovery from surgery, we induced sex change in the largest females on the reef by relocating all TP males to distant reefs. During the following week, we periodically checked the reefs for immigration of TP males from neighboring reefs and removed them, if found. If TP males were found repeatedly on a reef, we did not include those females in the study.

Seven days after TP removal, we observed experimental females on the reef during the spawning period (midday) and categorized each remaining experimental female as either dominant or subordinate (behavioral data not shown). As in a previous study (Godwin et al., 1996), dominant individuals were those displaying behavior that was typical of territorial TP males, including aggressively defending and actively courting on a spawning site, whereas subordinate individuals were not observed displaying any of these behaviors. Hence, on each reef, we had four classifications of individuals: dominant-ovariectomized (DO), dominant-sham (DS), subordinate-ovariectomized (SO), and subordinate-sham (SS). Immediately after the spawning period (2:30 P.M. to 4:00 P.M.), we captured experimental fish, transferred them to a small boat, and killed them with an overdose of the anesthetic tricaine methyl sulfonate. We then noted whether individuals had any permanent blue coloration, a TP male characteristic that develops reliably in DS females and not in DO females (Godwin et al., 1996). Color develops under the influence of $11 \mathrm{KT}$, as demonstrated by the field hormone treatments in experiment 3 and pilot experiments on captive ovariectomized females given $11 \mathrm{KT}$ (our unpublished data). To measure circulating levels of $11 \mathrm{KT}$, we immediately drew blood samples from the caudal vein, placed the samples on ice, and centrifuged these samples at $3000 \times g$ 2-6 hr later to collect plasma. Plasma was stored at -20 to $-80^{\circ} \mathrm{C}$ until analysis. To examine the AVT system, we removed the brains immediately after killing, immersion-fixed them in $4 \%$ paraformaldehyde for $25 \mathrm{hr}$, and then stored them in $0.1 \mathrm{M} \mathrm{PBS}$ at $4^{\circ} \mathrm{C}$ until cryosectioning. Finally, we dissected the bodies to verify the success of ovariectomies and determine the gonad identity (testes or ovary) of sham-operated individuals.

In 2001, we repeated the experiment with one design change. This design change was intended to determine whether the AVT system in subordinate females differed depending on whether they were subordinate to established TP males or to newly dominant and sex-changing individuals. Therefore, after females underwent surgery and were returned to their home reef, we manipulated the reefs to create either dominant or subordinate females. On reefs designated for dominant females $(n=2)$, we repeated the methods used in 2000 and relocated all TP males from the reef $2 \mathrm{~d}$ after surgery. From these reefs, we only collected females who became dominant on spawning sites. On reefs designated for subordinate females $(n=4)$, we controlled for disturbance associated with fish capture by catching TP males $2 \mathrm{~d}$ after surgery, holding them for $10 \mathrm{~min}$ in a net, and releasing them back on the focal reef. All females collected from these reefs remained subordinate to the TP males on the reefs. Consequently, in 2001, all subordinate females were subordinate to TP males rather than to sex-changers as in 2000. A second consequence of this altered design is that we were able to collect subordinate fish that were larger and therefore comparable in size with dominant fish collected in 2000. In addition, because of field complications, females in 2001 were sampled $10 \mathrm{~d}$ (rather than $7 \mathrm{~d}$ ) after TP males were removed and/or manipulated.

Field experiment 2: castration effects on dominant TP males. This experiment was designed to test the effects of castration on social status, territorial behavior, and AVT phenotype of territorial TP males. In 2000, we caught all TP males from large patch reefs and tagged them for individual identification using beaded floy tags (Floy Tag, Seattle, WA) (Warner and Schultz, 1992). Two to $3 \mathrm{~d}$ after tagging (to allow for assessment of whether TP males were territorial), we caught the territorial males in the morning (leaving the nonterritorial TP males on the reef throughout the entire duration of the experiment), either castrated them or performed a sham operation [8:00 A.M. to 11:00 A.M., using the same general surgical methods as outlined for ovariectomies by Godwin et al. (1996)], and then returned them to the reef before the spawning period. The number of castrated and sham-operated males was balanced across body size on each reef (range, 70.7-94.1 mm SL; mean, $85.5 \mathrm{~mm}$ ). We observed focal males $21-22 \mathrm{~d}$ after surgery in alternating $10 \mathrm{~min}$ time budgets throughout the spawning period, recording the frequency and duration of both courtships and aggressions and the frequency of inspections and spawns [for a detailed description of these behaviors, see Semsar et al. (2001)]. These data were used to verify territorial status in males. After the spawning period, we sampled the focal males as described above for females.

In 2001, we followed the same general experimental methods. However, because we had seen no clear behavior differences between treatments in 2000, we included additional behavioral observations and experiments to more fully test for differences between castrated and sham-operated males. First, 1-3 d after tagging, we observed males to obtain baseline behavioral measures for each on the same suite of behaviors noted above. Within $4 \mathrm{~d}$ of observing males, all territorial TP males on a reef were caught in the morning and either castrated or shamoperated and then held until the late afternoon ( 5:00 P.M.) and returned to the reef. Again, we balanced treatments across body size (range, 84.1-93.2 mm SL; mean, $88.9 \mathrm{~mm}$ ) but with a bias toward shamoperated males because we had recovered fewer sham-operated males in 2000. Two to $3 \mathrm{~d}$ after surgeries, we observed the focal males for the standard suite of territorial male behaviors. We exposed males to standardized behavioral tests designed to detect differences between treatments in responses to predators and TP male intruders 14-20 d after surgery. The predator test was performed first (14-16 d after surgery), and the intruder test was performed 2-4 d after the predator test (16-20 $\mathrm{d}$ after surgery).

To test responses to predators, a lizardfish (preserved and weighted) was introduced into the focal male's territory. The lizardfish, Synodus 
intermedius, is a sit-and-wait predator common on Teague Bay reefs, and preserved fish act as realistic model predators to blueheads (Warner and Dill, 2000). First, we recorded normal territorial behavior for $10 \mathrm{~min}$. We then presented the model to the focal male by waiting until the male was briefly away from his territory and placing the model within $0.5 \mathrm{~m}$ of the focal male's spawning site. When the focal male reentered its territory, we recorded the latency of the male to resume courting on its spawning site, the duration of time it spent on its territory, the frequency of bobs (a behavior commonly displayed in the presence of predators) (Warner and Dill, 2000), and the standard suite of territorial behaviors for two $10 \mathrm{~min}$ time budgets. We then removed the lizardfish model and recorded the latency of the focal male to resume courtship on its spawning site.

To test responses to intruder TP males, we presented focal males with a live TP male intruder housed in a Plexiglas tube $(8.2 \times 27.3 \mathrm{~cm}$ diameter; screened ends allowed water to flow through, a weight was strung with monofilament to the bottom, and a float was strung with monofilament $\sim 0.5 \mathrm{~m}$ above the tube). The same intruder was used in all trials and was smaller than each of the focal males ( $82.4 \mathrm{~mm} \mathrm{SL})$. During the spawning period, we placed the model within $0.5 \mathrm{~m}$ of the spawning site while the focal male was briefly away from its territory. Because the area defended by individual territorial males extends a minimum of several meters along the edge of reefs, these intruders were well within the focal male's territorial boundaries. When the focal male reentered its territory, we recorded the latency to first approach or contact with the tube and the frequency of approaches and contacts with the tube for $5 \mathrm{~min}$. Approaches were defined as the focal male approaching within one body length of the tube but not touching the tube. Contacts were defined as approaches ending in physical contact with the tube. Each approach or contact ended if the focal male turned away from the tube. After $5 \mathrm{~min}$, the intruder was removed from the site.

Finally, 21-23 d after surgery, we again observed the focal males in alternating periods of $10 \mathrm{~min}$ throughout the entire spawning period, recording all territorial and courtship behaviors during the focal sample. At the end of the spawning period, focal males were caught and sampled as described above.

Field experiment 3: 11KT effects on the AVT system in ovariectomized females. This experiment was designed to test the effect of $11 \mathrm{KT}$, the teleost androgen that induces secondary sexual characteristics (for review, see Borg, 1994), on the AVT system under conditions that socially inhibit sex change. We caught, tagged, and ovariectomized the largest four to eight females as described above (range, 57-70.1 mm SL; mean, $64.8 \mathrm{~mm}$ ) from patch reefs with two to five TP territories in Glover's Reef Atoll lagoon. Each female received an $8 \mathrm{~mm}$ Silastic implant $(\sim 20 \mu \mathrm{l}$; Silastic tubing, $1.47 \mathrm{~mm}$ inner diameter, $1.96 \mathrm{~mm}$ outer diameter; Dow Corning, Midland, MI) of either castor oil or castor oil plus $11 \mathrm{KT}$ (5 $\mu \mathrm{g} / \mu \mathrm{l}$; Steraloids, Newport, RI). The dose was chosen on the basis of effectiveness of implants used in goldfish (Stacey and Kobayashi, 1996) and pilot studies in bluehead wrasses showing that ovariectomized females implanted with this dose of $11 \mathrm{KT}$ showed full color development within 2 weeks, similar to natural sex changers, which take $\sim 3$ weeks ( 2 weeks after full testes development). In addition, although there are no published data on $11 \mathrm{KT}$ levels in the bluehead wrasse, the levels we induced here were comparable with those from intact TP males sampled from Glover's Reef in 1997 (mean, $1344 \pm 845$ pg/ml; range, 435-2900 $\mathrm{pg} / \mathrm{ml}$; K. Semsar, J. Godwin, M. Grober, unpublished data), and within the approximate range for TP males in other sex-changing fish (Cardwell and Liley, 1991; Hourigan et al., 1991). The implanted females were released the same day to their home reef, and no additional social manipulations were performed. Ten to $13 \mathrm{~d}$ after the surgery, we tested whether these females would respond to AVT by giving each a series of two intraperitoneal injections of saline and AVT ( $1 \mu \mathrm{g} / \mathrm{gm}$ body weight) on subsequent days [methods followed those of Semsar et al. (2001)]. The behavioral portion of this experiment is part of a larger and more comprehensive set of experiments addressing behavioral effects of exogenous AVT treatment across phenotypes, which is beyond the scope of this study. Fourteen to $16 \mathrm{~d}$ after surgery (and at least $2 \mathrm{~d}$ after hormone injections), we recaptured the females and photographed them to document color pattern differences and then collected blood and brain samples as described above.
All experimental methods described here were approved by and are in compliance with the guidelines of the Institutional Animal Care and Use Committee of North Carolina State University.

11-ketotestosterone assays. Levels of $11 \mathrm{KT}$ in unextracted plasma samples were assessed using an $11 \mathrm{KT}$ enzyme-linked immunostaining assay according to the directions of the manufacturer (ELISA kit 582751; Cayman Chemicals, Ann Arbor, MI). Because of small plasma volumes, particularly for smaller females and sex changers, only one $20 \mu$ laliquot of each sample was assayed, and sample sizes were small in some groups. Samples were incubated for $2 \mathrm{hr}$, and color development was read using a Bio-Tek Kinetic Reader (Bio-Tek Instruments, Winooski, VT). Unextracted plasma $11 \mathrm{KT}$ levels were then corrected using data from additional assays comparing unextracted and extracted plasma pool samples. To do this, we extracted a portion of the original plasma pool (derived from females, IP males, and TP males) twice with diethyl ether and ran these extracted samples and unextracted samples (original plasma pool) in parallel. In addition, a portion of these samples was spiked with a known amount of $11 \mathrm{KT}$. Although these comparisons did not assess the correction for the three phenotypes individually, measurements of the extracted versus unextracted pools and spiked aliquots from the pool were consistent in indicating that $11 \mathrm{KT}$ levels were underestimated by $43 \%$ in unextracted samples; therefore, unextracted values were divided by 0.57 .

AVT mRNA in situ hybridization. AVT mRNA relative abundances in the preoptic area (POA) of the hypothalamus were analyzed using in situ hybridization (ISH). The methods used are described briefly below and have been described in detail previously by Godwin et al. (2000). All brains were cryosectioned into six adjacent series of $20 \mu \mathrm{m}$ sections, and one series from each individual was used for ISH. For TP males from 2000, the ISH procedure used the same 33 mer degenerate antisense oligonucleotide probe for teleost AVT labeled with ${ }^{33} \mathrm{P}$ that was used by Godwin et al. (2000). For all females (2000 and 2001), sex-changers, and TP males from 2001, a specific antisense probe (5'-AACAATGTAGGTCTTGACAGGGGCTCCTCCCTT3-') based on the T. bifasciatum AVT sequence was used (GenBank accession number AY167033). Using a sense strand probe complementary to this sequence generates no signal, and previous RNase treatment eliminates signal (our unpublished data). Additionally, the pattern of labeling generated by both the homologous and degenerate oligonucleotide probes is identical to that generated with a homologous cRNA probe derived from a cloned T. bifasciatum AVT cDNA (our unpublished data).

Hybridization signal was primarily analyzed using GP phosphor screens (Kodak, Toronto, Ontario, Canada) that were exposed for $48 \mathrm{hr}$ immediately after completion of the assay and analyzed using a phosphor imager (Molecular Dynamics Storm System; Amersham Biosciences, Piscataway, NJ). Before the exposure of slides, screens were neutralized on a light table for $10 \mathrm{~min}$, as recommended by the manufacturer. Measures of background signal showed no differences between screens within experiments. In addition, slides within each experiment were randomly placed on screens with treatments intermixed to prevent biases that could result from differences among screens. Total hybridization signal for each was measured using Image Quant version $1.2 \mathrm{v}$ on a Macintosh Power personal computer. Because AVT labeling in the POA is limited to a discrete region in the center of the brain next to the third ventricle and nonspecific background signal is low with use of ${ }^{33} \mathrm{P}$-labeled oligonucleotides (Godwin et al., 2000), we quantified signal by defining regions of constant size across brains (large enough to always encompass all hybridization signal) on all sections showing signal and summing signal to arrive at whole POA measurements. The defined regions were large enough to cover all hybridization signals on the most densely labeled sections; therefore, on sections with less specific hybridization signal, background should represent a higher proportion of the total hybridization signal measured. This should reduce rather than magnify differences among groups and therefore provide conservative comparisons. Second, after exposure to phosphor screens, slides were dipped in NTB-2 emulsion (Kodak), exposed for $2 \mathrm{~d}$ at $4^{\circ} \mathrm{C}$, developed, and stained with cresyl violet to visualize cell bodies. Use of the emulsion technique also allowed assessment of the approximate contribution of signal from specific POA regions in the total hybridization signal measured by phosphor imaging. 


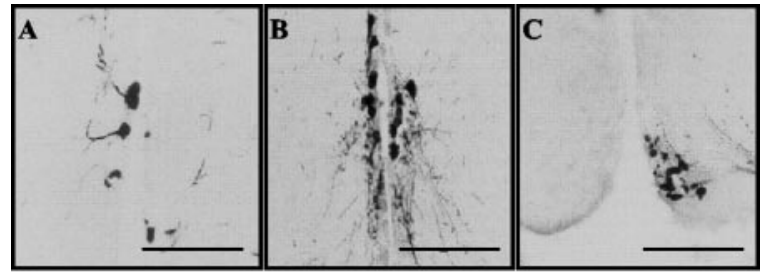

D

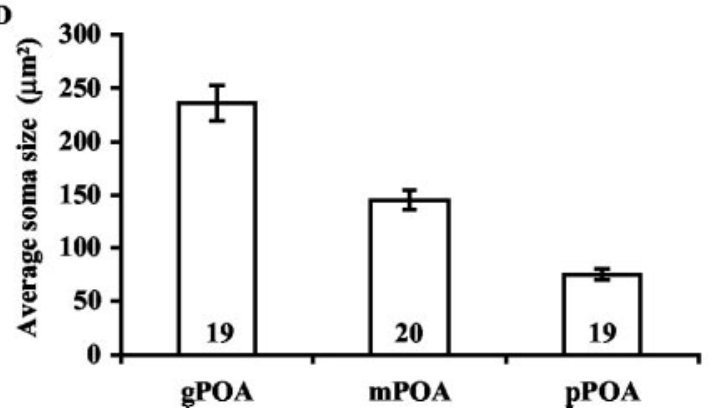

Figure 1. $A-C$, Photomicrographs of AVT-IR neurons in the gPOA $(A), \mathrm{mPOA}(B)$, and $\mathrm{pPOA}$ (C). D, Mean \pm SEM average AVT-IR soma sizes for TP males within each region of the POA. Sample sizes are indicated within bars. Scale bars, $100 \mu \mathrm{m}$.

Regions of consistent size placed over groups of cells in the POA were measured for average silver grain counts using Brain software (version 3.0; Drexel University Computer Imaging and Vision Center, Philadelphia, PA) on a Macintosh Power personal computer. Background was controlled by subtracting the measurement from an identically sized region located outside of the $\mathrm{POA}$ on the same section from the measurement of cells in the POA.

Importantly, independent measures of hybridization signal from phosphor imaging screens for both TP males and sex changers showed that 88 and $91 \%$, respectively, of total hybridization signal was accounted for by sections containing only gigantocellular and magnocellular neurons. In addition, total silver grain counts are significantly correlated with total hybridization signal $\left(R^{2}=0.73 ; p<0.0001\right)$. Except where noted, we present data on hybridization signal from phosphor imaging screens, because their large dynamic range prevents ceiling effects that can occur with silver grain counts.

For the ovariectomy experiment that examined the development of the AVT system, all slides from 2000 and 2001 were run in the same ISH procedure; therefore, comparisons between years could be made. For the castration experiment that examined the maintenance of the AVT system in TP males, males from each experimental year were run in a separate assay. Because hybridization signals depend on several assay-specific factors in ISH (e.g., label-specific activity, exposure time), we cannot distinguish whether differences between assays were attributable to assay or year differences in the castration experiment.

AVT immunocytochemistry. To examine AVT-immunoreactive (IR) cell size in the POA, a second series of slides from the original six series cut from each individual was analyzed using immunocytochemistry (ICC). Therefore, the POA from each individual in these experiments was analyzed by both ISH and ICC. Our ICC protocol followed that put forth by Foran and Bass (1998), using a primary antibody to rat AVP (DiaSorin, Stillwater, MN), peroxidase ABC kits (Vector Laboratories, Burlingame, CA) for secondary and tertiary antibodies, and DAB intensified with $0.3 \% \mathrm{NiCl}_{2}$. We estimated the number of AVT-IR cells and the average cross-sectional area of AVT-IR soma size in the POA using Brain software (version 3.0). Each cell was assigned to one of three POA nuclei on the basis of cell location, fiber extension, and descriptions of these areas as described by Braford and Northcutt (1983). These regions are the parvocellular POA (pPOA), located in the anteroventral POA often without obvious fibers (Fig. $1 \mathrm{C}$ ); the magnocellular POA (mPOA), located in the medial POA with obvious fiber extensions toward the pituitary (Fig. $1 B$ ); and the gigantocellular POA (gPOA), reported only in teleosts and located posterior and dorsal to the mPOA with fiber extensions that are not obviously directed toward the pituitary (Fig. 1A). We tested the appropriateness of using these criteria in assigning AVT-IR neurons to different POA regions and found that average AVT-IR soma sizes were significantly different among them (one-way ANOVA; $F=51.63 ; p<$ 0.001; all Tukey honestly significant difference comparisons; $p<0.05$ ) (Fig. $1 D$ ). In the gPOA and mPOA, we measured only AVT-IR cells showing at least one neurite. In the pPOA, we do not see neurites on cells in coronal sections. However, these cells are small (diameter, $\sim 5 \mu \mathrm{m}$ ), greatly increasing the likelihood that entire cells are represented within single sections (thickness, $20 \mu \mathrm{m}$ ).

Statistical analyses. ELISA data on $11 \mathrm{KT}$ plasma levels were analyzed with one-way ANOVA and Tukey-Kramer post hoc tests, where appropriate. Because of an inability to obtain plasma samples from each individual, only the subset of animals in which plasma samples were obtained is represented. Those individuals with levels of $11 \mathrm{KT}$ below detection limits were included with values assigned as the minimum detection limits for the assay.

There were no significant differences in body size among treatments in any of the experiments presented here $(p>0.3$ for all experiments). However, both measures of AVT expression, hybridization signal, and AVT-IR soma size are correlated with body size. Therefore, all subsequent analyses use data corrected for body size by dividing the respective measure by the standard length of the animal.

Total hybridization signal for AVT mRNA was analyzed using ANOVA and post hoc orthogonal contrasts where appropriate. In experiment 1 , in which all individuals were in the same assay, a three-way ANOVA compared the effects of year, dominance, and presence of gonads. In experiment 2 , in which each year was run in a separate assay, a two-way ANOVA compared the effects of assay and treatment. In experiment 3, a Student's $t$ test assessed the effect of treatment.

For analyses of AVT-IR POA soma sizes, no differences in cell size were found for animals from different experimental years in any experiment (including between females subordinate to TP males and those subordinate to sex changers; $p>0.1$ for all experiments), and data were therefore combined. Cell sizes from the gPOA, mPOA, and pPOA were analyzed separately. Sample sizes for the three POA regions do not always match because of the occasional loss of sections within a single area during ICC. The appropriate effects were again compared using ANOVA and post hoc orthogonal contrasts. In addition, potential correlations between average gPOA AVT-IR soma sizes and gPOA grains per cell were tested with Pearson's correlation.

Finally, behavioral experiments were analyzed using paired sample tests to compare frequencies and duration of behaviors and Fisher's exact tests to compare the occurrence of courtship and predator responses (see Table 2).

\section{Results}

\section{Effects of gonad removal and hormone implants on 11KT levels and color patterns}

Gonad removal and hormone replacements effectively generated differences in 11KT levels among treatment groups (Table 1). Despite small sample sizes in some groups in experiment 1 , females undergoing sex change with gonads (DS) had $11 \mathrm{KT}$ levels comparable with sham-operated TP males and higher levels than the other female groups (DO, SO, or SS; $p=0.02$ ). Importantly, all DS females showed the development of permanent blue coloration on the head, whereas none of the other treatment groups did, including the dominant ovariectomized females (DO). This coloration reliably develops under the influence of $11 \mathrm{KT}$ as mentioned above in Materials and Methods. In experiment 2, castrated males had significantly lower $11 \mathrm{KT}$ levels than shamoperated males ( $p=0.02$ ). In addition, all sham-operated males had blue skin healing around the surgical incision, whereas all castrated males had only white skin healing around the incision. In experiment 3, although once again we were able to collect only small numbers of plasma samples, the two samples from oil- 
Table 1. Mean and SEM of 11KT levels (in picograms per milliliter) in all three experiments

\begin{tabular}{llclc}
\hline ELISA & Number of samples & Mean $(\mathrm{pg} / \mathrm{ml})$ & SEM & $p$ value \\
\hline Experiment 1 & & & & $p=0.02$ \\
D0 & 4 & 55 & \pm 4 & \\
DS & 2 & 591 & \pm 413 & $*$ \\
S0 & 3 & 53 & \pm 17 & \\
SS & 7 & 140 & \pm 42 & \\
Experiment 2 & & & & $p=0.02$ \\
$\quad$ Sham & 11 & 645 & \pm 114 & \\
$\quad$ Castrate & 6 & 214 & \pm 93 & \\
Experiment 3 & & & & $p=0.09$ \\
$\quad$ Oil & 2 & ND & ND & ND \\
11KT & 6 & 1282 & \pm 186 & \\
\hline
\end{tabular}

The number of samples represents a subset of animals in which we were able to draw plasma. $p$ values refer to $t$ tests or ANOVA; asterisks indicate a significant difference from all other test groups within the experiment (TukeyKramer; $p<0.05)$. ND, Not determined.

treated females had nondetectable levels of $11 \mathrm{KT}$, whereas $11 \mathrm{KT}$ treated females had elevated $11 \mathrm{KT}$ levels.

\section{Experiment 1: social and gonadal influences during sex change}

\section{AVT mRNA abundance}

There was no effect of experimental year on AVT mRNA signal $(p>0.5)$, indicating that females subordinate to sex changers and those subordinate to TP males did not differ. Therefore, all SO and SS females from both years were grouped in subsequent analyses. The acquisition of dominance on a spawning site was associated with a nearly twofold increase in AVT mRNA signal ( $p=0.001$ ) (Fig. 2A), whereas the presence of gonads had no effect $(p=0.82)$ (Fig. $2 A$ ). This difference in AVT mRNA abundance between dominant and subordinate females appears to be attributable to differences in the mPOA for two reasons. First, sections containing parvocellular neurons only accounted for $9 \%$ of the hybridization signal as measured by phosphor imaging. Second, there was no significant effect of dominance on silver grain densities in the gPOA $(p=0.83)$ or $p P O A(p=0.11)$, whereas there was a significant difference in the $\mathrm{mPOA}(p=$ 0.035; data not shown).

\section{AVT-IR POA soma size and number}

The average AVT-IR soma size of the mPOA and pPOA did not vary across treatments. However, the average AVT-IR soma size in the gPOA of intact, sex-changing (DS) individuals was significantly larger than those in the three other treatment groups (orthogonal contrast, DS $>$ DO, SO, SS; $p=0.04$ ) (Fig. 2 B). However, increased gPOA AVT-IR soma size in DS individuals did not correlate with increased AVT mRNA signal in those neurons as measured by silver grains per cell $(p>0.1)$. There was no effect of treatment on AVT-IR cell number in any of the three nuclei ( $p>$ 0.1 for all experiments; data not shown).

\section{Experiment 2: castration effects on dominant TP males}

\section{AVT mRNA abundance}

Castration did not affect AVT mRNA signal ( $p=0.71$ ) (Fig. $3 A$ ). Although there was an effect of year and/or assay on hybridization signal ( $p<0.001$ ), this most likely represents assay differences typical of ISH rather than variation in message abundance between years (samples were run in two separate assays).
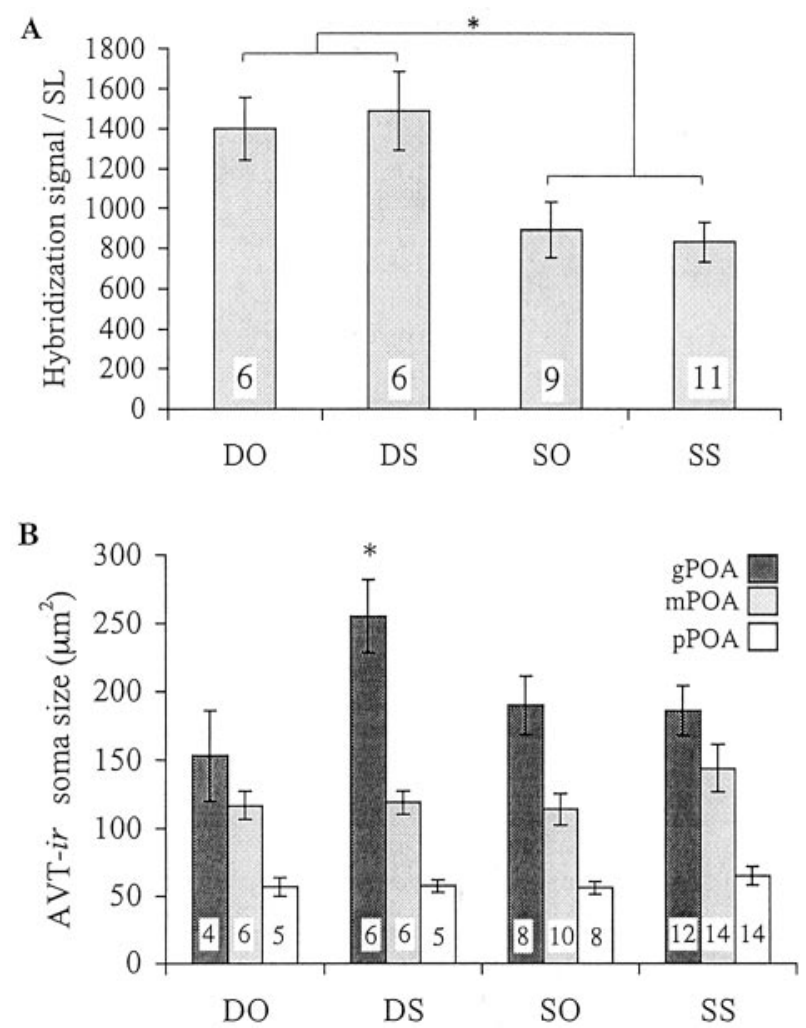

Figure 2. AVT neural phenotype from females in experiment 1. A, AVT mRNA hybridization signal (mean \pm SEM, standardized by body size). $B$, Mean \pm SEM average AVT-IR soma crosssectional area in the three POA regions. Sample sizes are indicated within the bars, and asterisks indicate significant differences among treatment groups (within P0A regions in B).

\section{AVT-IR POA soma size and number}

Average AVT-IR soma size did not differ between sham and castrated males in either the mPOA $(p=0.13)$ (Fig. $3 A$ ) or pPOA $(p=0.53)$ (Fig. $3 A)$. Average AVT-IR soma size in the gPOA was significantly larger in castrated males than in sham-operated males $(p=0.01$ ) (Fig. $3 A$ ). However, as with the DS group in the sex change experiment described above, average gPOA AVT-IR soma size did not correlate with AVT mRNA signal measured as grains per cell $\left(R^{2}=0.17 ; p>0.1\right)$. There was no effect of treatment on AVT-IR cell number in any of the three nuclei $(p>0.1$ for all experiments; data not shown).

\section{Behavior}

All TP males found on the reefs at the end of the experiments were territorial. No measure of male behavior in 2001 showed significant differences when compared either before and after surgery or between castrated and sham-operated males (Table 2).

\section{Experiment 3: 11KT effects on the APT/AVT system in ovariectomized females}

All ovariectomized females implanted with $11 \mathrm{KT}$ showed either full development of TP male coloration or were in the late stages of developing this coloration (blue head, green tail, near complete development of the black-white-black barring behind the pectoral fin insertion) during recapture. No females who received a control implant showed evidence of color change.

\section{AVT mRNA abundance}

In these socially subordinate and ovariectomized females, AVT mRNA expression did not vary with $11 \mathrm{KT}$ treatment $(p>0.1)$

(Fig. 4A) 

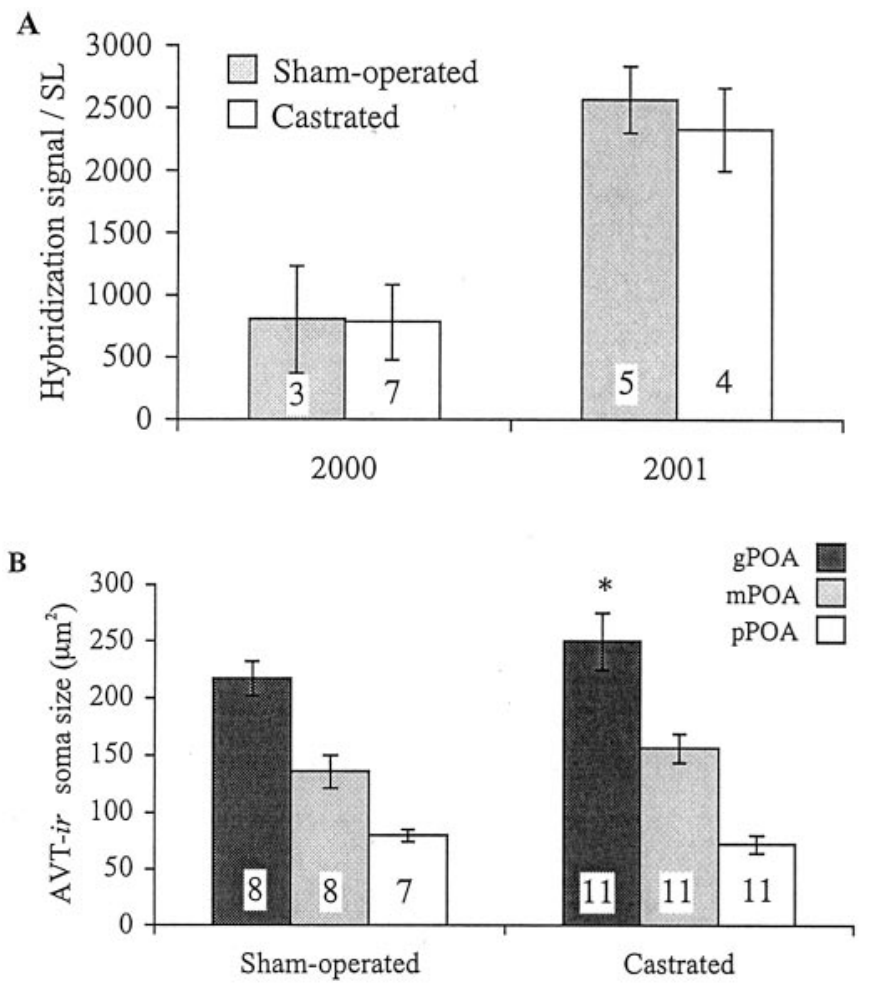

Figure 3. AVT neural phenotype from sham-operated and castrated TP males in experiment 2. A, AVT mRNA hybridization signal (mean \pm SEM, standardized by body size) from 2000 and 2001. B, Mean \pm SEM average AVT-IR soma cross-sectional area in the three POA regions. Sample sizes are indicated within the bars, and asterisks indicate significant differences among treatment groups (within POA regions in B).

Table 2. Measures and $p$ values of all behavioral tests from the TP male castration experiment conducted in 2001

\begin{tabular}{|c|c|c|c|c|}
\hline Behavior experiment & $\begin{array}{l}\text { Sample } \\
\text { size }\end{array}$ & Measure & Test & $p$ value \\
\hline \multirow{4}{*}{$\begin{array}{l}\text { Pre-Post Territorial } \\
\text { TP behavior }\end{array}$} & \multirow{4}{*}{$\begin{array}{l}\text { paired } \\
(\mathrm{n}=9)\end{array}$} & Courtship (f, dur) & Paired $t$ test & $0.45,0.19$ \\
\hline & & Aggression ( $f$, dur) & Paired $t$ test & $0.21,0.22$ \\
\hline & & $f$ of inspections & Paired $t$ test & 0.39 \\
\hline & & Spawning & Paired $t$ test & 0.71 \\
\hline \multirow[t]{2}{*}{ Response to predator } & $S=9$ & Presence of courtship & Fisher exact & 1 \\
\hline & $C=4$ & Presence of bobbing & Fisher exact & 1 \\
\hline \multirow{3}{*}{$\begin{array}{l}\text { Response to TP In- } \\
\text { truder }\end{array}$} & $S=6$ & fof approaches & Wilcoxon & 0.91 \\
\hline & $C=4$ & $f$ of contacts & Wilcoxon & 0.51 \\
\hline & & Latency to approach & Wilcoxon & 0.59 \\
\hline
\end{tabular}

f, Frequency; dur, duration; C, castrate male; S, sham control.

\section{AVT-IR POA soma sizes}

In socially subordinate and ovariectomized females, average AVT-IR soma sizes in all three POA regions did not vary with $11 \mathrm{KT}$ treatment $(p>0.1)$ (Fig. $4 B$ ). There was no effect of treatment on AVT-IR cell number in any of the three nuclei $(p>0.1$ for all experiments; data not shown).

\section{Discussion}

Gonadal sex steroids play critical roles in the organization and maintenance of sexually dimorphic brain systems in a variety of vertebrate species. These hormones are particularly important in the organization and activation of the AVP/AVT system and are an important mediator of male social behavior in well characterized rodent, amphibian, and avian models (for review, see Goodson and Bass, 2001; De Vries and Simerly, 2002). Although the AVP/AVT system can also respond to social influences (Delville
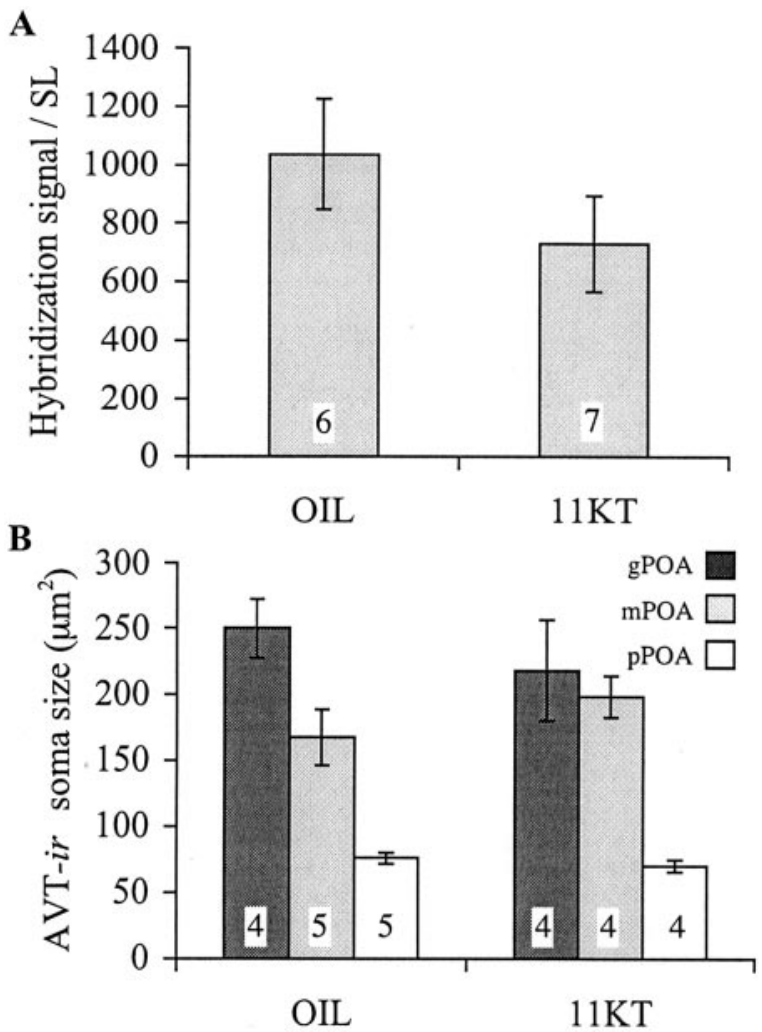

Figure 4. AVT neural phenotype from oil- and 11KT-treated females in experiment 3. A, AVT mRNA hybridization signal (mean $\pm \mathrm{SEM}$, standardized by body size). $B$, Mean $\pm \mathrm{SEM}$ average AVT-IR soma cross-sectional area in the three POA regions. Sample sizes are indicated within the bars.

et al., 1998), it is unclear to what degree these responses to social input are mediated through the hypothalamo-pituitary-gonadal (HPG) axis or other signaling systems in the brain. We show here that in bluehead wrasses, the AVT system can develop and be maintained independent of gonadal function. Therefore, bluehead wrasses provide an unusual and useful model to study how social environments can affect neuropeptide function through nongonadal pathways.

\section{AVT mRNA abundances are predicted by behavior}

Many fish, especially sex-changing species, rely on social cues rather than the ontogenetic maturation of gonads to initiate and orchestrate the development of the dominant phenotype (Warner, 1988). Studies to date have focused primarily on how social cues modulate the HPG axis to affect both morphological characters and neural substrates of behavioral characters (Grober et al., 1991; Francis et al., 1993; Fernald, 2002). However, in bluehead wrasses, the development of dominant male behavior in natural sex-changers can precede the change of ovaries to testes (Warner and Swearer, 1991) and occurs even if females are ovariectomized (Godwin et al., 1996). We show here that this gonadindependent switch from female to male behavior is accompanied by a gonad-independent increase in AVT mRNA abundance in the mPOA. The mPOA and gPOA of fish are considered homologous to the paraventricular nucleus of tetrapods (Braford and Northcutt, 1983). Although the mPOA does project to the pituitary, both nuclei also project to at least the telencephalon and the thalamus in trout (Saito et al., 2002). Therefore, it is likely that AVT changes in these regions could directly alter neural function in other brain areas.

All three experiments show that during the development and 
maintenance of the dominant male phenotype, social cues and changes in social status can alter AVT mRNA abundance through pathways independent of gonadal status and circulating $11 \mathrm{KT}$. First, among dominant sex changers, individuals with functioning gonads (DS) and correspondingly higher $11 \mathrm{KT}$ levels show no additional increase in AVT mRNA abundances over ovariectomized individuals (DO), although both groups have significantly higher AVT mRNA abundances than subordinate groups. Second, castrated TP males show AVT mRNA abundances similar to those of sham-operated males despite significantly reduced $11 \mathrm{KT}$ levels. Finally, even ovariectomized females given high circulating $11 \mathrm{KT}$ levels (experiment 3 ) exhibit low AVT mRNA abundances when kept under natural socially subordinate conditions.

Although neither the presence of testes nor $11 \mathrm{KT}$ predicted AVT mRNA abundances in these experiments, AVT mRNA levels were predicted by the presence of dominant male behavior. Consistent with the findings here, M. Grammer and J. Godwin (unpublished data) found lower preoptic area AVT mRNA abundances in TP males that did not hold territories relative to TP males that did, but no difference was found between nonterritorial TP males and female-mimic initial-phase males. Together, these findings indicate that the display of dominant male behavior predicts AVT mRNA abundances, whereas gonadal androgen production is not necessary for either increased or sustained production of AVT mRNA. This issue is considered in detail below.

\section{Social, gonadal, and regional differences interact to affect AVT-IR soma size}

Instead of a clear effect of dominance, as with AVT mRNA abundances, we found that social status, gonadal status, and POA region interact to influence AVT-IR soma size. AVT-IR soma sizes in the mPOA and pPOA did not vary with treatment, either during sex change or after castration in TP males. However, in the gPOA, intact sex-changing (DS) individuals had significantly larger AVT-IR soma sizes for their body size compared with the DO, SS, and SO groups, indicating a rapid increase in AVT-IR soma size accompanying the assumption of dominance only when testes had developed. Because the absolute AVT-IR soma size (i.e., not corrected for body size) of DS individuals was similar to the much larger TP males of the castration experiment, gonadal input may serve to rapidly increase the size of AVT-IR neurons to that characteristic of fully developed TP males. AVT-IR soma size in the gPOA of TP males is also affected by castration. However, in this case, intact TP males have smaller AVT-IR soma sizes than castrated males.

Bluehead wrasses are not the only teleost fish to display complex interactions between social and gonadal factors regulating neuropeptide neuron size. In another well characterized teleost model, the African cichlid Haplochromis burtoni, the assumption of territorial status in males leads to larger testes, higher $11 \mathrm{KT}$ levels, and larger gonadotropin-releasing hormone (GnRH)-IR soma sizes in the POA (Francis et al., 1993; for review, see Fernald, 2002). However, castration of Haplochromis males leads to additional increases in GnRH-IR soma size, whereas androgen replacement reverses these effects (Francis et al., 1993).

Changes in AVT-IR soma size in the gPOA are unlikely to be solely attributable to direct effects of gonadal androgen production. Similar to findings in goldfish (Parhar et al., 2001), exogenous $11 \mathrm{KT}$ did not alter the AVT-IR soma size in any POA region in the socially subordinate, ovariectomized females in this study or in intact, laboratory-housed bluehead wrasse females (McIntryre, 1998; cf. Grober and Bass, 2002). Testosterone (T) also appears unlikely to be the cause of these changes, because females have higher circulating $\mathrm{T}$ levels than males in many fish, including a congener of the bluehead wrasse, Thalassoma duperrey (Nakamura et al., 1989; for review, see Borg, 1994). Although T and the aromatization of $\mathrm{T}$ into estrogen mediate many androgendependent sex differences in mammals (De Vries and Simerly, 2002), what little is known about the link between aromatization of $\mathrm{T}$ and social status in fish suggests that aromatase may block the masculinization of behavior by preventing the conversion of T to $11 \mathrm{KT}$ (Forlano et al., 2001).

Other gonad-influenced neural systems may link gonadal function to POA cell size. For example, GnRH expression is associated with both sex change and social status [T. bifasciatum (Grober et al., 1991) and H. burtoni (Francis et al., 1993)] and tightly correlated with gonadal function (for review, see Foran and Bass, 1999). Direct links between GnRH and AVT systems have yet to be examined, but interactions between the systems are likely to influence male-typical reproductive behavior (Foran and Bass, 1999). Serotonin and dopamine are also associated with social status through effects on aggression and dominance (Fernald, 2002). Serotonin influences AVP release in hamsters (Ferris et al., 1997), and both neurotransmitters are coregionalized with AVT in the POA of bluehead wrasses (J. Elkins, J. Reed, and Godwin, unpublished data).

The mechanism by which AVT-IR soma sizes in the gPOA are affected is intriguing, because it suggests that different aspects of neuronal phenotype, such as size and neuropeptide production, may be influenced independently. However, the significance of these phenomena in T. bifasciatum is unclear, because differences in AVT-IR soma sizes were not consistently linked to either the increased AVT mRNA abundances (either overall or within the gPOA) or differences in expression of male-typical behavior. Instead, the relative abundances of AVT mRNA did closely correlate with and predict the expression of male-typical behavior. Studies in other fish also suggest a better agreement between AVT mRNA abundance and behavioral expression than with soma size. For example, in Salaria pavo, a fish with reversed sex roles in which females court males, AVT mRNA is expressed in greater abundance per cell in females, despite the fact that males who have higher $11 \mathrm{KT}$ levels have larger AVT-IR soma sizes (Grober et al., 2002).

Although the patterns described here are in contrast to those in examples in which the AVP/AVT system is strongly androgen dependent, the regulation of neuropeptide systems should be considered in light of the environment that an animal occupies (Crews and Moore, 1986). Social hierarchies and mating opportunities change quickly and unpredictably for bluehead wrasses. Individuals assuming dominant social roles may have to rapidly increase their display of aggression and territorial defense to suppress these behaviors in other individuals. In bluehead wrasses, the ability to decouple neuropeptide pathways mediating male behavior from testicular function may allow sex-changing females to more rapidly assume dominant behavior and, therefore, suppress sex change and dominant behavior in other individuals.

Together, our results suggest that: (1) unlike in most models, AVT mRNA abundances typical of the dominant male phenotype in bluehead wrasses can both develop and be maintained independent of gonadal inputs, (2) AVT mRNA is a better predictor than AVT-IR soma size of male behavior, and (3) various aspects of neuronal phenotype can respond differentially to hormonal/ social signals. Gonad-independent effects (e.g., social influences) on the AVP/AVT system may be common across species but more difficult to discern in many models because of the strong influences of gonadal androgens. 


\section{References}

Arnold AP, Breedlove SM (1985) Organizational and activational effects of sex steroids on brain and behavior: a reanalysis. Horm Behav 19:469-498.

Borg B (1994) Androgens in teleost fishes. Comp Biochem Physiol C Pharmacol Toxicol Endocrinol 109:219-245.

Braford Jr MR, Northcutt RG (1983) Organization of the diencephalon and pretectum of the ray finned fishes. In: Fish neurobiology (Davis RE, Northcutt RG, eds), pp 117-164. Ann Arbor, MI: University of Michigan.

Cardwell JR, Liley NR (1991) Androgen control of social status in males of a wild population of stoplight parrotfish, Sparisoma viride (Scaridae). Horm Behav 25:1-18.

Crews D, Moore MC (1986) Evolution of mechanisms controlling matingbehavior. Science 231:121-125.

Crews D, Coomber P, Baldwin R, Azad N, Gonzalez-Lima F (1996) Brain organization in a reptile lacking sex chromosomes: effects of gonadectomy and exogenous testosterone. Horm Behav 30:474-486.

Delville Y, Melloni RH, Ferris CF (1998) Behavioral and neurobiological consequences of social subjugation during puberty in golden hamsters. J Neurosci 18:2667-2672.

De Vries GJ, Simerly RB (2002) Anatomy, development, and function of sexually dimorphic neural circuits in the mammalian brain. In: Hormones, brain and behavior, Vol 4 (Pfaff DW, Arnold AP, Etgen AM, Fahrbach SE, Rubin RT, eds), pp 137-192. San Diego: Academic.

Fernald RD (2002) Social regulation of the brain: status, sex, and size. In: Hormones, brain and behavior, Vol 2 (Pfaff DW, Arnold AP, Etgen AM, Fahrbach SE, Rubin RT, eds), pp 435-444. San Diego: Academic.

Ferris CF, Melloni Jr RH, Koppel G, Perry KW, Fuller RW, Delville Y (1997) Vasopressin/serotonin interactions in the anterior hypothalamus control aggressive behavior in golden hamsters. J Neurosci 17:4331-4340.

Foran CM, Bass AH (1998) Preoptic AVT immunoreactive neurons of a teleost fish with alternative reproductive tactics. Gen Comp Endocrinol 111:271-282.

Foran CM, Bass AH (1999) Preoptic GnRH and AVT: axes for sexual plasticity in teleost fish. Gen Comp Endocrinol 116:141-152.

Forlano PM, Deitcher DL, Myers DA, Bass AH (2001) Anatomical distribution and cellular basis for high levels of aromatase activity in the brain of teleost fish: aromatase enzyme and mRNA expression identify glia as source. J Neurosci 21:8943-8955.

Francis RC, Soma K, Fernald RD (1993) Social regulation of the brain pituitary-gonadal axis. Proc Natl Acad Sci USA 90:7794-7798.

Gladfelter WB, Gladfelter EH (1987) Fish community structure as a function of habitat structure on West Indian patch reefs. Rev Biol Trop 26:65-84.

Godwin J, Crews D, Warner RR (1996) Behavioural sex change in the absence of gonads in a coral reef fish. Proc R Soc Lond B Biol Sci 263:1683-1688.

Godwin J, Sawby R, Warner RR, Crews D, Grober MS (2000) Hypothalamic arginine vasotocin mRNA abundance variation across sexes and with sex change in a coral reef fish. Brain Behav Evol 55:77-84.

Goodson JL, Bass AH (2001) Social behavior functions and related anatom- ical characteristics of vasotocin/vasopressin systems in vertebrates. Brain Res Brain Res Rev 35:246-265.

Grober MS, Bass AH (2002) Life history, neuroendocrinology, and behavior in fish. In: Hormones, brain and behavior, Vol 2 (Pfaff DW, Arnold AP, Etgen AM, Fahrbach SE, Rubin RT, eds), pp 331-348. San Diego: Academic.

Grober MS, Jackson IMD, Bass AH (1991) Gonadal-steroids affect LHRH preoptic cell number in a sex-role changing fish. J Neurobiol 22:734-741.

Grober MS, George AA, Watkins KK, Carneiro LA, Oliveira RF (2002) Forebrain AVT and courtship in a fish with male alternative reproductive tactics. Brain Res Bull 57:423-425.

Hourigan TF, Nakamura M, Nagahama Y, Yamauchi K, Grau EG (1991) Histology, ultrastructure, and in vitro steroidogenesis of the testes of two male phenotypes of the protogynous fish, Thalassoma duperrey (Labridae). Gen Comp Endocrinol 83:193-217. McIntyre KK (1998) Arginine vasotocin in the preoptic area of the bluehead wrasse and the effects of 11-ketotestosterone. MS thesis, Arizona State University.

McIntyre KK (1998) Arginine vasotocin in the preoptic area of the bluehead wrasse and the effects of 11-ketotestosterone. MS thesis, Arizona State University.

Nakamura M, Hourigan TF, Yamauchi K, Nagahama Y, Grau EG (1989) Histological and ultrastructural evidence for the role of gonadal-steroid hormones in sex change in the protogynous wrasse Thalassoma duperrey. Environ Biol Fishes 24:117-136.

Parhar IS, Tosaki H, Sakuma Y, Kobayashi M (2001) Sex differences in the brain of goldfish: gonadotropin-releasing hormone and vasotocinergic neurons. Neuroscience 104:1099-1110.

Sachs B, Meisel RL (1994) The physiology of male sexual behavior. In: The physiology of reproduction (Knobil E, Neill J, eds), pp 3-106. New York: Raven.

Saito D, Komatsuda M, Urano A (2002) Intrinsic organization and extrahypothalamic projections of magnocellular vasotocin and isotocin neurons in the trout brain. Soc Neurosci Abstr 28:471.8.

Semsar K, Kandel FLM, Godwin J (2001) Manipulations of the AVT system shift social status and related courtship and aggressive behavior in the bluehead wrasse. Horm Behav 40:21-31.

Stacey N, Kobayashi M (1996) Androgen induction of male sexual behaviors in female goldfish. Horm Behav 30:434-445.

Stoddart DR (1962) Three Caribbean atolls: Turneffe Islands, Lighthouse Reef, and Glover's Reef, British Honduras. Atoll Res Bull 87:1-151.

Warner RR (1988) Sex change in fishes: hypotheses, evidence, and objections. Environ Biol Fishes 22:81-90.

Warner RR, Dill LM (2000) Courtship displays and coloration as indicators of safety rather than of male quality: the safety assurance hypothesis. Behav Ecol 11:444-451.

Warner RR, Schultz ET (1992) Sexual selection and male characteristics in the bluehead wrasse, Thalassoma bifasciatum: mating site acquisition, mating site defense, and female choice. Evolution 46:1421-1442.

Warner RR, Swearer SE (1991) Social control of sex change in the bluehead wrasse, Thalassoma bifasciatum (Pisces, Labridae). Biol Bull 181:199-204. 